\title{
The Experimental Concentration Optimization of the Binary System of Oil Displacement in Offshore Oilfield
}

\author{
Li Liu \\ Key Laboratory of Enhanced Oil and Gas Recovery \\ of Ministry of Education of China \\ Northeast Petroleum University \\ Daqing, China \\ E-mail: liuliduoduo@163.com
}

\author{
Xue Wan \\ Petroleum Engineering \\ Northeast Petroleum University \\ Daqing, China \\ E-mail: 1585612604@qq.com
}

\author{
Nan Chen \\ Petroleum Engineering \\ Northeast Petroleum University \\ Daqing, China \\ E-mail: 490984123@qq.com
}

\author{
Yanfu Pi \\ Key Laboratory of Enhanced Oil and Gas Recovery \\ of Ministry of Education of China \\ Northeast Petroleum University \\ Daqing, China \\ E-mail: piyanfu@163.com \\ Yu Wang \\ Honggang Oil Production Plant of Jilin Oilfield \\ Jilin Oilfield \\ Songyuan, China \\ E-mail: 1048897269@qq.com
}

\begin{abstract}
In view of the formation characteristics as the high viscosity and the high permeability of offshore heavy oil reservoir, simulation of artificial core was developed. The indoor physical simulation experiments under the offshore oil field reservoir conditions were conducted. The effective viscosity of the binary system in the core was determined by the experiment. The corresponding capillary number was calculated according to the effective viscosity and experiments measured the relation curve between the capillary number and the oil displacement efficiency. When the capillary number gets higher, the system recovery efficiency is higher, and the residual oil saturation is lower. With the capillary number increasing, the increase scope of recovery and the decrease scope of residual oil saturation both increase gradually; The capillary number exists a critical value when the order of magnitude between $10^{-2} \sim 10^{-3}$. When the capillary number is greater than the critical value, it can improve the displacement efficiency greatly. When the capillary number is around $10-1$, the oil displacement efficiency and the residual oil saturation tend to be stable. According to the capillary number and oil displacement efficiency curve, optimize the binary system in which the polymer concentration is $1750 \mathrm{mg} / \mathrm{l}$ and the surface active agent concentration is $0.2 \%$.
\end{abstract}

Keywords-Offshore oil field; binary system; capillary number; oil displacement efficiency; polymer concentration

\section{INTRODUCTION}

The sustained growth of production in offshore oil field has become an important part for the replacement of the oil production. With the increase of difficulty of exploration and the efficient development of offshore oil and gas resources, it is imperative to develop techniques that can greatly improve the oil recovery in offshore oil field [1-2]. Polymer flooding and binary system flooding as the most potential chemical flooding technology is the first choice after the water flooding displacement for the offshore oil field. According to the current conditions of reservoir and the present situation of mining of Suizhong36-1[3-4], this article did the chemical flooding indoor experiments with the binary complex system mixed with the polymer AP-P5 and surface active agent $\mathrm{BH}-\mathrm{M} 2$. The related production and research units had researched the related parameters of the binary system [5], which had been applied in other blocks of offshore oil field. The performance of the reagent is relatively good. This article will mainly screen the composition concentration for the binary system, and use the method of the relation curve between the capillary number and the oil displacement efficiency to optimize it.

\section{THE DETERMINATION OF THE RELATION CURVE BETWEEN THE CAPILLARY NUMBER AND THE OIL DISPLACEMENT EFFICIENCY}

\section{A. Capillary Number Effect on Oil Displacement Efficiency}

Only under the condition of building a certain pressure gradient where the two phase fluids can flow in the porous media. It can be expressed by formula (1): 


$$
\frac{d P}{d x}=\frac{\sigma_{\mathrm{ow}}}{K_{\mathrm{w}}} N_{\mathrm{C}}
$$

Type: $\sigma_{o w}$-The interfacial tension between oil and displacement fluid;

$\mathrm{K}_{\mathrm{w}^{-}}$Under the water saturation porous media on the effective permeability of water phase;

$\mathrm{N}_{\mathrm{C}}$-Capillary number, a dimensionless quantity just depends on the geometric features of the porous medium which has wettability.

According to the Darcy's law of multiphase seepage, the general expression of capillary number can be given:

$$
N_{\mathrm{C}}=\frac{\mu_{\mathrm{W}} v}{\sigma}
$$

Type: $\mu_{\mathrm{x}}$-seepage velocity; $v$ - the real speed

\section{B. The Calculation Method of Capillary Number [6-7]}

At home and abroad, the research in terms of capillary number has been studied more deeply. There exist a variety of ways about the calculation methods of capillary number. Many of the calculation methods need specific reservoir conditions, so they lack of the unified and effective calculation methods. Aimed at this situation, this article conducted a lot of research. Through comprehensive comparison, the following methods were optimized as the ways of capillary number calculation under the condition of the heavy oil reservoir in the offshore.

1) The calculation of seepage rate

Firstly, calculate the average porosity of cores by the known core parameters.

$$
\phi=\frac{V_{p}}{V_{f}}
$$

Type: $\phi$-average porosity; $\mathrm{V}_{\mathrm{p}}$-pore volume; $\mathrm{V}_{\mathrm{r}}$-rock core volume.

Then calculate the area of core:

$$
S=\frac{V_{f} \times \phi}{L}
$$

Type: L -core length; $S$-the core of the area.

Calculate the original oil saturation according to the measured data from the oil saturation stage in the experimental process of core:

$$
S_{o i}=\frac{V_{o i}}{V_{f} \times \phi}
$$

Type: $\mathrm{S}_{\mathrm{oi}}$-original oil saturation; $\mathrm{V}_{\mathrm{oi}}$-saturated oil volume

Derive the residual oil saturation through the original oil saturation [8]:

$$
S_{\text {or }}=S_{\text {oi }} \times\left(1-E_{R}\right)
$$

Type: $\mathrm{S}_{\mathrm{or}}$ - residual oil saturation; $\mathrm{S}_{\mathrm{oi}}$-original oil saturation; $\mathrm{E}_{\mathrm{R}}$ - total recovery ratio.

Because the injection rate is known (set to $1 \mathrm{ml} / \mathrm{min}$ ), calculate the seepage velocity according to the obtained data above:

$$
V_{s}=\frac{v}{S \times\left(1-S_{o r}\right)}
$$

Type: $V_{s}$ - seepage velocity; $\mho$ - injection rate; $\mathrm{S}$ - the core of the cross section area.

2) Viscosity processing method

Select the binary system solution viscosity with polymer of $1750 \mathrm{mg} / \mathrm{l}$ and surface active agent of $2000 \mathrm{mg} / 1$ as the test object. This article uses the method by laying the test point on the $90 \mathrm{~cm}$ long core to test the change of distance and the binary system viscosity (as shown in Fig. 1). The data graph is shown in Fig. 2.

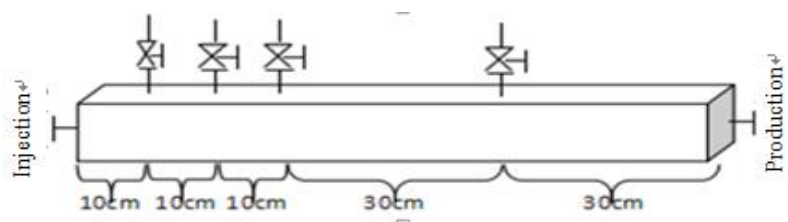

Figure 1. The signal fig of working viscosity test in core

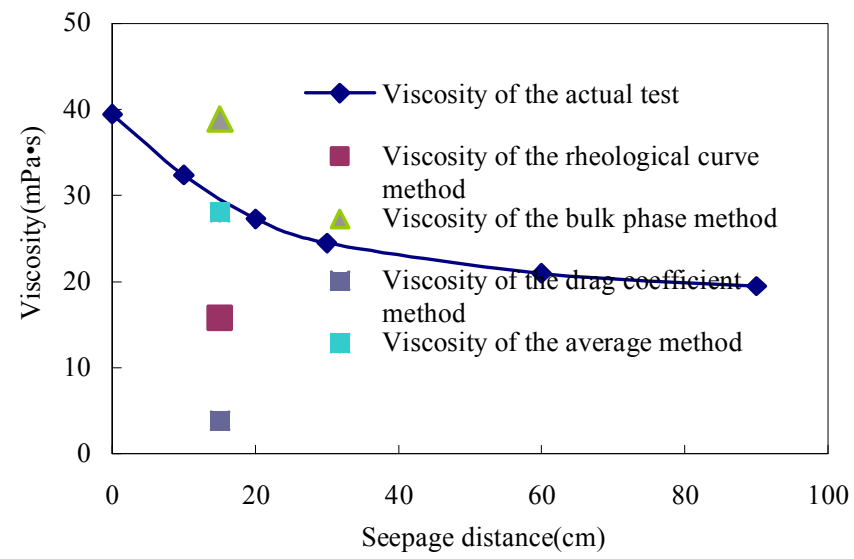

Figure 2. The change of viscosity along the flow direction

The viscosity curve fitting formula is: $y=0.0039 \mathrm{X} 2$ $0.554 \mathrm{X}+38.155$. Put $\mathrm{L}=15 \mathrm{~cm}$ in, and get the viscosity of $30.72 \mathrm{mPa} \cdot \mathrm{s}$. At $30.72 \mathrm{mPa} \cdot \mathrm{s}$ as the effective viscosity in the process of core displacement, comparing the value of viscosity calculated with the above methods, the calculation result with the average viscosity method is the most closed to the work viscosity of core.

3) Calculate the value of capillary number according to the measured data of the interfacial tension before the experiment

$$
N_{C}=\frac{\mu \times V_{s}}{\sigma}
$$

Type: $\mu$ - system viscosity; $\sigma$ - the interfacial tension.

According to the known core parameters of the target oil field in the offshore and the data from the indoor simulation experiment, put the average viscosity, oil/water interfacial tension and the displacement speed of binary compound system into the classic formula (8) of capillary number, and calculate the corresponding capillary number to different binary recognition formula. 


\section{The Experimental Scheme}

Due to the approximate scope of the seepage velocity can be estimate according to the site condition, $3.6 \times 10^{-}$ ${ }^{5} \mathrm{~m} / \mathrm{s}$ is selected for estimated average of seepage velocity. So the concentration of the displacing phase solution and the capillary number can be changed by the way of controlling the concentration of the polymer and the surface active agent [9]. Set a total of 31 group schemes of binary compound system solution (as shown in Table1) and 1 group scheme of water flooding.

TABLE I . MEASURED VISCOSITY OF DIFFERENT CONCENTRATIONS OF THE POLYMER/SURFACTANT FORMULATION

\begin{tabular}{|c|c|c|c|c|c|}
\hline \multirow{2}{*}{$\begin{array}{l}\text { Serial } \\
\text { number } \\
\text { of } \\
\text { schemes }\end{array}$} & \multicolumn{2}{|c|}{ concentration } & \multicolumn{3}{|c|}{ viscosity $(\mathbf{m P a} \cdot \mathbf{s})$} \\
\hline & $\begin{array}{c}\text { Polymer } \\
\text { solution(m } \\
\text { g/l) }\end{array}$ & $\begin{array}{c}\text { The } \\
\text { surfact } \\
\text { ant } \\
(\%)\end{array}$ & $\begin{array}{c}\text { The } \\
\text { before } \\
\text { injecti } \\
\text { on }\end{array}$ & $\begin{array}{c}\text { The } \\
\text { effective }\end{array}$ & $\begin{array}{c}\text { The } \\
\text { Outlet }\end{array}$ \\
\hline 1 & 500 & 0.01 & 6.20 & 4.70 & 3.20 \\
\hline 2 & 700 & 0.01 & 12.1 & 8.90 & 5.70 \\
\hline 3 & 850 & 0.01 & 14.40 & 10.45 & 6.50 \\
\hline 4 & 1250 & 0.01 & 20.50 & 14.55 & 8.60 \\
\hline 5 & 1500 & 0.01 & 27.60 & 18.90 & 10.20 \\
\hline 6 & 500 & 0.02 & 6.30 & 4.90 & 3.50 \\
\hline 7 & 700 & 0.02 & 14.40 & 11.20 & 8.00 \\
\hline 8 & 850 & 0.02 & 14.70 & 10.90 & 7.10 \\
\hline 9 & 1250 & 0.02 & 22.20 & 15.30 & 8.4 \\
\hline 10 & 1500 & 0.02 & 28.10 & 19.10 & 10.10 \\
\hline 11 & 500 & 0.05 & 6.80 & 5.10 & 3.40 \\
\hline 12 & 700 & 0.05 & 13.90 & 10.70 & 7.50 \\
\hline 13 & 850 & 0.05 & 15.50 & 11.40 & 7.30 \\
\hline 14 & 1250 & 0.05 & 21.40 & 15.10 & 8.80 \\
\hline 15 & 500 & 0.08 & 5.60 & 4.40 & 3.20 \\
\hline 16 & 700 & 0.08 & 13.50 & 10.30 & 7.10 \\
\hline 17 & 850 & 0.08 & 15.30 & 11.60 & 7.90 \\
\hline 18 & 1250 & 0.08 & 22.30 & 15.40 & 8.50 \\
\hline 19 & 1250 & 0.10 & 21.70 & 15.30 & 8.90 \\
\hline 20 & 1500 & 0.10 & 27.40 & 18.40 & 9.40 \\
\hline 21 & 1750 & 0.10 & 39.60 & 26.70 & 13.80 \\
\hline 22 & 2000 & 0.10 & 49.10 & 31.80 & 14.50 \\
\hline 23 & 1250 & 0.15 & 21.10 & 14.40 & 7.70 \\
\hline 24 & 1500 & 0.15 & 27.30 & 18.50 & 9.70 \\
\hline 25 & 1750 & 0.15 & 39.70 & 26.40 & 13.10 \\
\hline 26 & 2000 & 0.15 & 48.70 & 31.50 & 14.30 \\
\hline 27 & 1250 & 0.18 & 21.60 & 14.60 & 7.60 \\
\hline 28 & 1500 & 0.18 & 28.10 & 18.90 & 9.70 \\
\hline 29 & 1750 & 0.18 & 39.10 & 26.30 & 13.50 \\
\hline 30 & 1250 & 0.20 & 21.80 & 15.20 & 8.60 \\
\hline 31 & 1750 & 0.20 & 39.80 & 28.10 & 16.40 \\
\hline
\end{tabular}

The experiment scheme to measure the relation curve of capillary number and oil displacement efficiency of binary complex flooding:

After water flooding to the moisture content of $70 \%$, inject binary complex system solution continuously until the outlet of core out oil. As a contrast, conduct an experiment of pure water flooding until the outlet of core out oil.

\section{Interfacial Tension and Viscosity Measurement}

1) Using the Model TX500C interface tension meter measure the values of interfacial tension.

\begin{tabular}{|c|c|c|c|c|c|c|c|}
\hline \multicolumn{7}{|c|}{ Different concentration } \\
\hline $\begin{array}{c}\text { Surf } \\
\text { acta } \\
\text { nt } \\
(\%)\end{array}$ & \multicolumn{7}{|c|}{} \\
\hline & 500 & 700 & 850 & 1250 & 1500 & 1750 & 2000 \\
\hline 0.01 & 0.14 & 0.15 & 0.17 & 0.14 & 0.12 & - & - \\
\hline 0.02 & 0.08 & 0.04 & 0.10 & 0.09 & 0.07 & - & - \\
\hline 0.05 & 0.03 & 0.04 & 0.05 & 0.06 & - & 0.04 & - \\
\hline 0.08 & 0.02 & 0.04 & 0.03 & 0.03 & - & - & - \\
\hline 0.10 & - & - & - & 0.04 & 0.04 & 0.02 & 0.02 \\
\hline 0.15 & - & - & - & 0.02 & 0.02 & 0.02 & 0.02 \\
\hline 0.18 & - & - & - & 0.01 & 0.07 & 0.01 & 0.01 \\
\hline 0.20 & - & - & - & 0.01 & 0.00 & 0.00 & 0.01 \\
\hline
\end{tabular}

The data is shown in TABLE II.

TABLE II . THE INTERFACIAL TENSION OF BINATRY SYSTEM WITH DIFFERENT FORMULATIONS $(\mathrm{mN} / \mathrm{m})$

2) Viscosity meter: Brinell digital display viscometer with the water bath of constant temperature DV-III.

The measurement results are shown in Table1.

With the advance process in the core, the viscosity of the displacement fluid decreased because of the shearing action in the core. So the measurement of average effective viscosity of binary complex system solutions in the process of displacement becomes an important link to calculate capillary number accurately. This experiment by measuring the former static viscosity and the outlet viscosity of the binary solution after the injection becomes stable, with the average value as the effective viscosity. It with characteristics as simple operation, accurate measurement and the data is representative, etc. It can representatively reflect the average effective viscosity called $\mu$ of the binary composite system solution in the core flow shear process.

\section{THE EXPERIMENT RESULTS ANALYSIS}

\section{A. The Relation Curve between Capillary Number and Oil Displacement Efficiency}

According to the classic capillary number formula and the recovery efficiencies of different schemes get from the oil displacement experiments of 32 formulas, calculate the capillary number, and get the oil displacement efficiency under different capillary numbers. Get the relation curve between capillary number and oil displacement efficiency 
and the relation curve between capillary number and the residual oil saturation by the experimental data from the oil displacement experiments with 31 groups of binary systems, which as shown in Fig. 3.

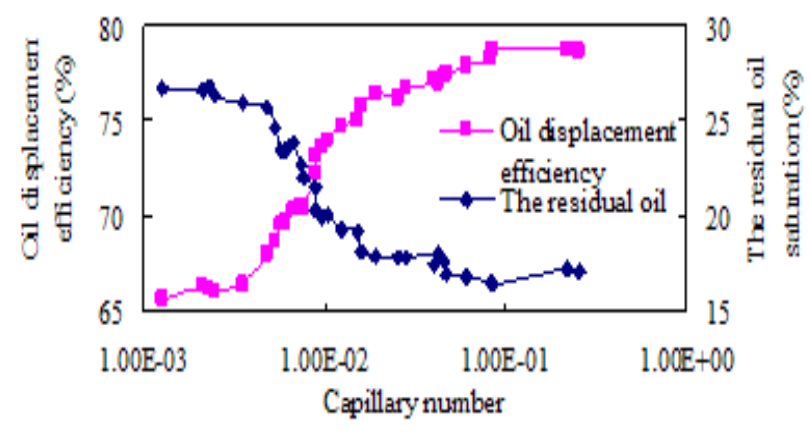

Figure 3. Relation curve of capillary number and oil displacement efficiency and residual oil saturation in typical offshore block

\section{B. Analysis of Experimental Results of the Relation between Capillary Number and Oil Displacement Efficiency}

1. With the increase of capillary number, oil displacement efficiency increase gradually. When $\mathrm{N}_{\mathrm{C}}=1 \times 10^{-3}$, oil displacement efficiency is about $65 \%$. When $\mathrm{N}_{\mathrm{C}}$ increases to $1 \times 10^{-1}$, oil displacement efficiency can reach $78 \%$. Capillary number curve exists turning point (about $4 \times 10^{-3}$ ) within the range of $10^{-3} \sim 10^{-2}[7]$. Under the condition of the value of capillary number is less than turning point, oil displacement efficiency increases with the increase of capillary number, but the oil displacement efficiency increase more gently. When the capillary number is greater than the turning point, the amplification of oil displacement efficiency increased obviously. The results show that the capillary number between $10^{-3} \sim 10^{-2}$ orders of magnitude exists a critical value and oil displacement efficiency can be improved to a great extent only by increasing the capillary number to greater than the critical capillary number.

2. With the increase of capillary number, residual oil saturation decrease. When $\mathrm{N}_{\mathrm{C}}=1 \times 10^{-3}$, residual oil saturation is approximately $27 \%$. When the capillary value reaches $1 \times 10^{-1}$, residual oil saturation decreased to $17 \%$.

3. The descend range of residual oil saturation increase gradually with the increase of capillary number. When the capillary number is small, the descend range is relatively gentle. When the capillary number is greater than the critical capillary number, the descend range increase significantly, and it achieve stability until drop to around $17 \%$.

Given the study of capillary number and oil displacement efficiency, this article optimized the corresponding binary system. The polymer solution concentration is $1750 \mathrm{mg} / \mathrm{l}$ and the surface active agent mass concentration is $0.2 \%$.

\section{CONCLUSIONS}

1. The average of the injection viscosity and the viscosity of produced liquid is closer to the effective viscosity of binary system at the core for the experimental core with the length of $300 \mathrm{~mm}$ and permeability of $2500 \times 10^{-3} \mu \mathrm{m}$.

2 . In the binary system, the descend range of residual oil saturation increase gradually with the increase of capillary number. Oil displacement efficiency can be improved to a great extent only by increasing the capillary number to greater than the critical capillary number.

3. According to the capillary number and oil displacement efficiency curve, in the optimization of binary system the polymer concentration is $1750 \mathrm{mg} / \mathrm{l}$ and the surface active agent mass concentration is $0.2 \%$.

\section{ACKNOWLEDGEMENTS}

The research work was joint funding between the national major projects "Reservoir Research for Enhanced Oil Recovery Technology after Polymer Flooding in Offshore Oilfields" (2011ZX05024-004-14).

\section{REFERENCES}

[1] Zenglin Wang, Xinwang Song, Yangwen Zhu, ect. "The Key Technology of Enhanced Oil Recovery for Binary Combination Flooding in Offshore Oilfield," Petroleum Geology and Oil Recovery, vol.21, Mar.2014, pp. 5-6.

[2] Chuanfei Wang. "The Evaluation Research of Reservoir Potential of Enhanced Oil Recovery for Chemical Flooding in Offshore Oilfield-Taking Suizhong 36-1 Reservoir as an Example," China University of Petroleum, 2010.

[3] Xiansong Zhang, Engao Tang, Xiaoqing Xie, ect. "The Research of Development Characteristics for Injection Polymer at Early and Injection Mode in Offshore," Journal of Oil and Gas, vol.25, Jul.2013, pp. 123-124. doi:10.3969/j.issn.1000-9752.2013.07.026.

[4] Kanyun Li. "The Formulating of Binary Combination Flooding in Offshore Oilfield," China University of Petroleum, 2011. doi:10.7666/d.y1876260.

[5] Xinmin Zhang, Yongjun Guo, Rusen Feng, ect. "The Performance Study of the Binary Compound Drive System Suitable for the Suizhong 36-1 of Bohai Oilfields," Oil Field Chemical, vol.29, Sept.2012, pp. 322-325.

[6] Shangqi Zhai. "The Effect of Capillary Number on Oil Displacement Efficiency of Polymer-surfactant System," Northeast Petroleum University, 2014.

[7] Tao Dai, Kaihua Xi, Jialin Dai, ect. "The Method of Binary Flooding Reservoir Simulation Based on the Capillary Number Interpolation," Journal of Shandong university (science edition), vol.47, Aug.2012, pp. 55-59.

[8] Wei Yan. “The Influence Research of Different Drive System on Recovery Ratio and Residual Oil Saturation," Daqing Petroleum Institute, 2007. doi:10.7666/d.y1049282.

[9] Yanhua Liu, Bailing Kong, Shuai Lv, ect. “A Study on Enhanced Oil Recovery of Binary Combinational Flooding after Polymer Flooding in Heavy Oil Reservoir," Oil Field Chemical, vol.28, Sep.2011, pp. 288-291.

[10] Lingyun Chen. "Experimental Study of Viscoelasticity of Polymer and Interfacial Tension of System Effect on Oil Displacement Efficiency," Daqing Petroleum Institute, 2002. 